\title{
Karl Miller, MD
}

\author{
Karl Miller ${ }^{1}$
}

Published online: 19 December 2018

(C) Springer Science+Business Media, LLC, part of Springer Nature 2018

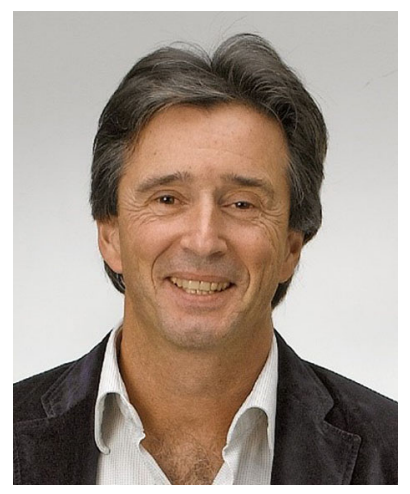

Dr. Karl Miller, Professor of Surgery, associated with the University of Innsbruck, is one of the pioneers in laparoscopic bariatric surgery. He has spent more than 32 years practicing general surgery of which he dedicated 22 years to the development and perfection of bariatric surgery. He is world renowned for being an avant-guard clinical researcher, a leading practitioner, a passionate teacher, and an exceptional mentor. $\mathrm{He}$ is credited for developing laparoscopic techniques such as the "pars flaccida" technique for placing Gastric Bands, "circular stapling techniques" for performing the Gastric Bypass, and endoluminal obesity surgery, all considered groundbreaking procedures in the surgical treatment of Obesity and Metabolic diseases.

Dr. Miller attended the Medical College at the University of Innsbruck, Austria where he graduated in 1983 followed by a residency in general surgery at Salzburg General Hospitalthis was here where his inquisitive mind and forward thinking led him to an early interest in laparoscopic surgery in 1989 . He kept perfecting his laparoscopic skills in order to start implementing them into bariatric surgery. In 1992, he

Karl Miller

karl@miller.co.at

1 Surgical Department, Diakonissen \& Wehrle Private Hospital, Salzburg, Austria performed the first laparoscopic Gastric Band placement in Austria, and in 2000, the laparoscopic Roux-en-Y gastric bypass. In 2001, Dr. Miller was named the Head of Surgical Department at Hallein Hospital in Austria, where his focus on laparoscopic bariatric surgery continued to grow, along with his early conviction of the necessity of a multidiscipline treatment approach for the treatment of obesity. This led him to become one of the pioneers in implementing this comprehensive practice in obesity management. Dr. Miller's careerlong focus on bariatric surgery allowed him to perform more than 4500 laparoscopic bariatric cases, establishing him as one of the leading figures in this specialty. His worldwide reputation in bariatric surgery attracted to his practice patients with severe and advanced conditions, ranging from challenging revision surgeries to super-obese patients with BMIs reaching as high as $161 \mathrm{~kg} / \mathrm{m}^{2}$. Amazingly, all of these challenging patients were treated laparoscopically.

In addition to his devotion to his patients and to his clinical practice, Dr. Miller has also demonstrated a great interest in clinical research. This interest attracted him to an extensive undertaking of scientific studies in general surgery. As a result, he has authored or co-authored over 100 peer-reviewed articles published in international medical journals, in addition to 21 books and book chapters and 12 DVD and multimedia productions. Dr. Miller's dedication to research earned him the prestigious recognition from the Journal Obesity Surgery that granted him the Annual Outstanding Author Award. His wide experience as an author made him a valuable contributor to the Editorial Boards of several prestigious journals such as Obesity Surgery, Surgery for Obesity and Related Diseases, World Journal of Gastrointestinal Endoscopy, Videosurgery and Miniinvasive Techniques, and Archives of Obesity.

Dr. Miller is also active in several medical societies. In 1994, Dr. Miller became a founding member of the Austrian Society for the Surgery of Obesity and Metabolic Disorders. He served as its President from 2001 to 2015. He also served as the President of the Austrian Obesity Academy from 1996 to 2011 and is its current Vice President. Dr. Miller is also a founding member of the International Federation of the Surgery of Obesity and Metabolic Disorders (IFSO) where 
he was also President 2010-2011 and Congress President in 2015 in Vienna. Dr. Miller is a Fellow of the American College of Surgeons and member of numerous other national and international societies.

Finally, Dr. Miller's passion for education and training has enabled him to establish his department as a Center of Excellence in Bariatric Professional Education, attracting more than 700 bariatric surgeons from across the world eager to learn from him and benefit from his expertise. His commitment to supporting the wider community of bariatric surgeons with education and training has resulted in his participation as a faculty member for several world renowned training institutions such as IRCAD Strasbourg, France; the European Surgical Institute Hamburg, Germany; the Surgical Institute University Sharjah, United Arab Emirates; and the Sri Aurboindo Institute of Medical Sciences Medical College in Indore, India. His vision of advancing the field of bariatric surgery through knowledge sharing and education allowed him to establish the Alpine Obesity Surgery Expert Meeting, which became an annual forum bringing bariatric experts from across the world in order to share their experiences and advance this discipline. Doctor Miller is frequently invited to perform live surgeries and demonstrations at numerous forums across the world allowing him to perform over 100 live transmission cases and deliver more than 400 lectures in international congresses throughout his career.

For the body of his work and efforts in the field of bariatric surgery, IFSO honored Doctor Miller by giving him the "IFSO Golden Pin Award." For that, he is not only grateful to the society for recognizing his work, but he is also deeply grateful to his mentors, namely Doctor Emanuel Hell and Doctor Nicola Scopinaro.

Dr. Miller's hometown, which he enjoys with his wife Rola, is in Salzburg. They are the proud parents of Sabrina, Sandro, Jana, and Thea. They enjoy skiing, gardening, and playing volleyball. Dr. Miller is also a passionate golfer and an eager windsurfer.

Publisher's Note Springer Nature remains neutral with regard to jurisdictional claims in published maps and institutional affiliations. 